faces behind them, the limb must necessarily be lengthened.

If these statements and arguments are correct, it seems to be proved that, in incomplete luxations of the tibia backwards, flexion, and not extension, is the easiest mode of reduction, and that in such cases the limb may be lengthened.

P.S. As there seems to be a question respecting the influence of bleeding or loss of blood in the production of softening of the brain, I may mention that $I$ was re. cently called in to a woman who had a "fit" on the ninth day after a very easy labour, with very little loss of blood. I found her slightly paralysed in the right hand and arm, but unable to speak plainly, or to find the right word to express her meaning. The left pupil was natural, perhaps a little dilated; but the right was very much contracted. Since the attack the previous night, she had vomited, and had diarrhœa, the last mo. tion being bloody mucus. I ordered her a chalk mixture with landanum, the first dose of which stopped the vomiting and diarrhoa. The next (third) day she com plained of pain in the left side of her head; and I ordered four leeches, which were not applied till the night of the fourth day, when only two drew blood, at the outer angle of the eye, about six o'clock. At 11 P.x. she had another fit, became insensible, and remained so tili her death, twenty-four hours after the attack, with occasional convulsive movements of the affected arm. I saw her twelve hours after the attack, when the eyes presented the same appearance. I did not examine the head; but the symptoms clearly point to softening of the brain, rather than apoplexy; and I cannot believe that the small quantity of blood drawn by two leeches could have caused a recurrence of the "fit". Her eldest son has epileptic fits; and I am disposed to attribute the mother's disease to perhaps a tendency to disease of the brain, increased by grief at the recent death of her father, and brought to a climax by the straining of even an easy labour. The absence of pain till after the fit is accounted for by the insensibility of the cerebral sub. stance.

\section{CASE OF PELLAGRA.}

By Sayuel Wilks, M.D.

THE observations of Dr. Peacock on pellagra, contained in the last number of the NIedico.Chirurgical Review, have again brought before my mind a case which $I$ witnessed last autumn, and which I suggested might be an example of an affection which is almost peculiar to the north of Italy. No English author that I am aware of, has ever described such a form of disease in this country, and, therefore, it is with considerable dif. fidence that $I$ bring forward the present case as an example of it; at the same time the case so much resembles the descriptions which I had read of this remarkable malady, that I informed the medical man under whose care the patient had been, that I could make nothing of it unless it were a case of pellagra. The report of the case, althnugh brief, may be the means of drawing some similar instance from the note-books of other practi. tioners. I believe it to be true that many diseases which are rife in some countries, and almost peculiar to them, may occur in isolated instances, und in modified characters, in other parts of the world; and, thus it is that elephentiasis or leprosy may be sometimes met with in our own temperate island. In the same way, pellagra, which is described by French writers as not occurring in Paris, yet was supposed to exist in the persons of four patients which were in La Charité scome years ago. (M. Willemin in Archives Générales de Médecine, Series 4, vol. xiii.)

The disease, as it is witnessed in Italy, is an affection of a very chronic nature, continuing for several years, characterised by a general wasting of the body, and by a rash which covers the exposed parts of the skin, commencing as an erythema, and progressing into a lichenous or eczematous eruption. At a later period, sores sometimes appear, impairment of digestion, and nervous symptoms, a paralysis of the limbs. The cause of the disease appears at present not decided, it having been thought by some that it is due to exposure to the sun, from the fact of exacerbations occurring in the summer time; by others, that it is due merely to poverty, as it does not prevail amongst the rich; but these and similar supposed theories, are refuted by the remembrance that such causes are not peculiar to Lombardy, but exist where pellagra is quite unknown. The most recent theory places the cause in the consumption of diseased maize, the corn being affected somewhat after the manner of the ergotised rye.

In the four cases which occurred at Paris, described by M. Willemin, and which appeared to be true examples of the disease, the skin was covered either with an erythematous, a lichenous, or eczematous rash. This was on the face and arms, and had a thickly defined margin; in two cases a diarrhœa existed; in one the gums were spongy, as in scurvy, and in some there was a weakness of the extremities. The pulse was feeble in all, and in one case, after the patient bad been lying down, was reduced to thirty beats in the minute.

The peculiarities of the disease appear to be: in the first place, this cutaneous eruption, which is remarkable in affecting the parts exposed to the light, as the face, neck, chest, backs of hands, arms, or feet, the redness ceasing abruptly at a line where the covering of the clothes commences; the skin also becoming hard and dry like parchment, and in some cases bullæ appearing. Next in imporiance to the cutaneous rash, are various nervous symptoms, as numbness or pains in the limbs, and sometimes a veritable paralysis, as in myeitis of the spinal cord. It is said by some writers that in very bad examples of the disease, a melancholy overtakes the patient determining to suicide, especially by drowning, and to this has been given the special name of hydromania. Other writers, however, are ignorant of the existence of this propensity. As regards the pathology of the disease, nothing is known; some have regarded it as a chronic gastro-enteritis; whilst others, at a loss to discover the seat of the disease, have been content to style it morbus chronicus totius corporis.

The case which came before me last autumn, was that of a woman, living at Glastonbury, and intimately known to $\mathrm{Mr}$. Malton of that place. This gentleman sent the case up to his relative Dr. Charlton of Dartford, who again brought her to me for an opinion as to the nature of her complaint, the obscurity of which suggested to the former gentleman, I apprehend, that there might be some disease of the suprarenal capsules. She was married, aged 33, and had three children. She informed me that she had been ill for six years, having become very thin and being covered in parts with an eruption. She said that her illness had commenced five and a half years before, in the month of May, after exposure to the sun. These statements were not extracted from her by leading questions; for it was not until after she had left my house, and I was revolving the case in my mind, that the idea struck me, that it was one of pellagra. Soon after this exposure to the sun, a rash appeared on the face and arms, and subsequently she lost flesh and became weak. This rash, she said, had continued ever since with varied severity, being aggravated in summer, and better in winter. Her general appearance was very remarkable, presenting as she did a withered and emaciated look, reminding one of a child in the last.stage of marasmus; all the outlines of the face were very prominent, the cheeks were sunken in and the temporal muscles much wasted. The face was covered with a 
brownish.red rash, not uniform in amount but patchy; this was of a papular or lichenous char acter, with a slight furfuraceous covering. The neck was slightly affected in the same manner; the forearms as far as the elbows were covered with a similar rash; the skin being rough and affected by a brownish-red eruption. This appeared to correspond to the papules of the slin, and gave a hard dry feel to the touch. The backs of the hands were similarly affected, and, in fact, all those parts which were exposed, whilst those which were covered were free. Her limbs were wasted, and the joints of the elbows somewhat contracted; not admitting of full extension. On the face there was also the scab of a pustule, and on the arm was another similar one. On the right fore. arm there was also an ulcer, the seat of a former pastule, and which was unhealthy looking an i bleeding. I could discover no disease in the body, for tuberculosis suggesting itself, I looked for phthisis and other manifestations of it, but nothing of the kind could be discovered. I also examined for enlargement of the cervical glands which might have obstructed the thoracic duct; nothing could be felt in the abdomen, allhough I surmised the presence of mesenteric disease. The only nervous symptom was weakness of one arm. The gums presented no marlied scorbutic appearance, but were rather too red and swollen. There was no diarrhœa, and she stated that her spirits were good.

It will be seen that the symptoms in this ease very closely correspond to those described as belonging to pellagra; and, therefore, no surprise will be felt when I suggested to Dr. Charlton the nature of the disease. If it should not be of this lind it will be found probably due to some morbid condition interfering with the due supply of chyle to the system, and in connection with this, it will be remembered how harsh and withered the skin becomes in children who are wasting from mesen teric disease. It is not surprising, therefore, that the disease has been called (according to Dr. Peacock) marasmus pellagrosus, or tabes pellagro;a.

Within the last few days, Mr. Malton has written to say that the patient is going on much the same; the wound in the arm is still ulcerating; and she has lost almost complete power of the same extremity. The disease of the skin is better (winter time). Mr. Malton will, no doubt, report the further progress of the case.

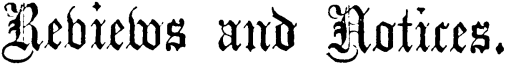

The Nature and Treatment of Gout and Rheumatic Gout. By Alfred Baring Garkod, M.D. F.R.S., Fellow of the Royal College of Physicians ; Physician to King's College Hospital; etc. Second Edition, enlarged and carefully revised Pp. 618. London: 1863.

When the first edition of this work appeared, three years ago, we gave an ample analysis of its contents (Joursal, Jan.7, 1860). It is therefore not necessary for us now to do more than state that Dr. GARrod has in this edition incorporated the results of his increased experience of the nature and treatment of gout; and has added a chapter on the diseases to which gouty persons are peculiarly liable. At the same time, he has pruned down the historical and other less practically important matter contained in the first edition, so that the present volume contains but a few pages more than its predecessor. The work shows traces throughout of careful revision; but the author bas nowhere found reason to alter the views formerly expressed by him. His opportu- nities of testing them, he says, "have only tended to confirm his opinion as to their accuracy."

Ciminical Surgery. On Stricture, Retention of URINe, Stone in the BladDer, aNd other Diseases of the Urinary Organs. By Thomas Bryant, F.R.C.S., Assistant-Surgeon, etc., Guy's Hospital. Londan: 1862.

Mr. Bryant here furnishes a continuation of his valuable series of surgical clinical observations. His remarks are here founded on 1077 cases of diseases of the bladder and urethra, admitted into Guy's Hospital between October 1st, 1853, and March 30th, 1861 : of these, 1008 wore cured or relieved, and 77 died.

Among the practical matters which the author has brought forward, we observe that rupture or laceration of the urethra assumes a very different meaning in the Guy's Hospital practice when it occurs as the result of stricture from that which it has when it follows an injury in a healthy urethra. In the former category, $4 \tilde{J}$ cases occurred, of which 15 died; in the latter were 19 cases, and no deaths. This difference in the result is, assuming the treatment in both classes to be equally prompt, no doubt due to the fact that, in the former class, the urine has been long retained in a distended portion of the urethra behind the stricture, and, when extravasated, has become more or less altered from its proper character: in the latter, when urine is extravasated (which does not always occur), it is urine pur et simple that is poured out. In all cases, early incision into the perinæum is the practice to be followed ; and in cases of extravasation from stricture, Mr. Bryant recommends that the stricture itself be divided at the same time that the incision is made in the perinæum. In cases of ruptured urethra from injury, the following is the line of practice recommended by Mr. Bryant, and apparently followed at Guy's Hospital.

"If called to a patient who has evidently been the subject of an injury to the urethra, suffering from simple retention, the first object of the surgeon should be to attempt to pass a catheter; if the urethra is not completely torn away, and there is not much blood locally effused, there will be a strong probability that he will succeed, and, having done so, the instrument should be left and fastened in; a gum elastic instrument, therefore, with a strong stilette, should be employed. If the attempt at catheterism, although having been fairly made, should fail, some other meaus must be employed; for it is clear that an outlet for the urine must be obtained, or otherwise extravasation, with its dangers, will necessarily follow.

"An incision into the perinæum with a grooved staff is unquestionably the soundest practice; by it the extravasated blood and urine, if it exists, finds a ready outlet; and the bladder, when it contracts, will find a vent for its contents, without the dangers occasioned by an extravasation of urine.

"If the orifice of the vesical end of the ruptured urethra can be found with a grooved probe, a catheter should be passed, the instrument having been first in. troduced through the penis, and subsequently guided upon the grooved probe into the bladder; if difficulty is experienced in finding the orifice, there need be no alarm, as it is quite clear that the urine will readily find its way externally through the artificial wound; an early attempt to pass a catheter should, nevertheless, certainly 